\title{
A Case of Systemic Lupus Erythematosus Associated with Drug-Induced Liver and Erythema Multiforme-Like Lesions Which Was Mostly Consistent with the Rowell Syndrome
}

\author{
Yuefei Pan ${ }^{1 *}$, Haixia Feng ${ }^{2}$ \\ ${ }^{1}$ Disease Prevention and Control Section, Army 81st Group Military Hospital, Zhangjiakou, China \\ ${ }^{2}$ Department of Dermatology, The First Affiliated Hospital of Henan University of Science and Technology, Luoyang, China \\ Email:^106654186@qq.com
}

How to cite this paper: Pan, Y.F. and Feng, H.X. (2020) A Case of Systemic Lupus Erythematosus Associated with Drug-Induced Liver and Erythema Multiforme-Like Lesions Which Was Mostly Consistent with the Rowell Syndrome. Case Reports in Clinical Medicine, 9, 242-246.

https://doi.org/10.4236/crcm.2020.98034

Received: August 4, 2020

Accepted: August 21, 2020

Published: August 24, 2020

Copyright $\odot 2020$ by author(s) and Scientific Research Publishing Inc. This work is licensed under the Creative Commons Attribution International License (CC BY 4.0).

http://creativecommons.org/licenses/by/4.0/

\begin{abstract}
Rowell syndrome is a disease diagnosed by three major and three minor criteria. The major criteria include the presence of lupus erythematosus (systemic, discoid, or subacute lupus), EM-like lesions (with or without involvement of mucous membranes), and a speckled pattern of antinuclear antibodies. The minor criteria include chilblains, anti-Ro and/or anti-La antibodies, and positive RF. In this article, we present a patient whose manifestation indicated RS, because his diagnosis of Systemic lupus erythematosus was definite, and also onset with EM-like lesions and positive antinuclear antibodies. All these above are consistent with the three major criteria. In addition, his RF was positive, which was the complement for the minor criteria.
\end{abstract}

\section{Keywords}

Systemic Lupus Erythematosus, Erythema Multiforme-Like Lesions, Rowell Syndrome

\section{Introduction}

Systemic lupus erythematosus (SLE) is a chronic, inflammatory autoimmune disease with multi-organ system involvement. Early clinical manifestations include skin lesions, fever, and fatigue. Other systemic symptoms include weakness and liver damage [1]. Erythema multiforme (EM) is considered a type $1 \mathrm{~V}$ hypersensitivity reaction often associated with medication use and sometimes caused by a viral infection. It rarely manifests as a complication of SLE or disco- 
id lupus erythematosus (DLE). One study described Rowell syndrome by four patients with chronic DLE associated with EM who demonstrated the characteristic immunologic pattern of a speckled type of antinuclear factor (ANA), anti-SjT type of precipitating antibody to saline extract of human tissues, and rheumatoid factor (RF) [2] [3]. We present a case of systemic lupus erythematosus (SLE) with concomitant EM-like lesions, which shared many similarities with Rowell syndrome (RS). The informed consent of the patient was obtained in this study.

\section{Case Report}

A 16-year-old boy presented to us on December $12^{\text {th }} 2017$ with a 5 month history of intermittent fever and fatigue, deep yellow urine phenomenon for 14 days, hand-foot rash, cracked bleeding lips and diarrhea for approximately 10 days before hospitalization. The patient had no history of drinking ethanol, no drug abuse and no history of hemorrhage or viral-associated liver disease.

His physical examination showed that he was febrile $\left(39.6^{\circ} \mathrm{C}\right)$, and target-shaped erythema was present on his hands and feet (Figure 1(a), Figure 1(b)). Furthermore, the patient had chapped and bleeding lips, ulcerated oral mucosa, and his pharynx was covered with a white pseudomembrane (Figure 2). His skin and sclera were icteric, his abdominal muscles were tense, his upper abdomen was tender and the patient had a positive murphy's sign. In addition, both lower extremities had slight edema.

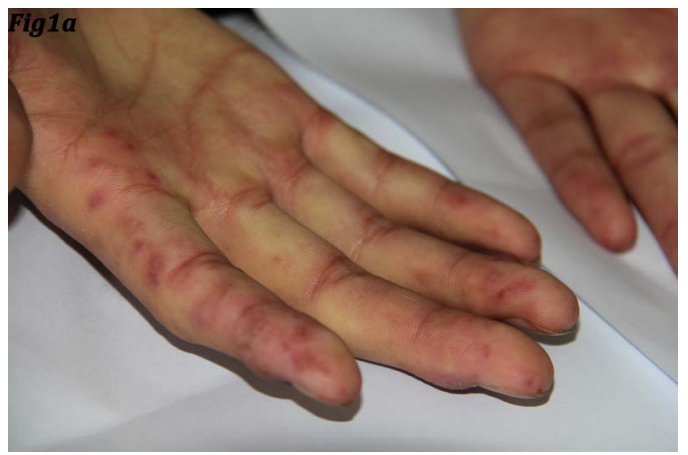

(a)

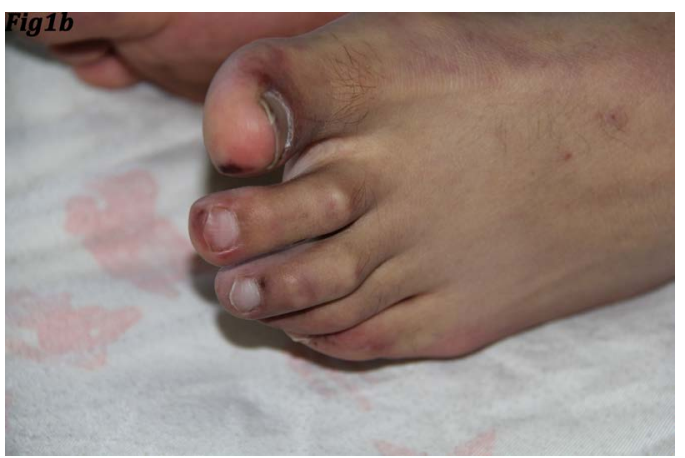

(b)

Figure 1. Target-shaped erythema was present on his feet and hands. 
Auxiliary laboratory examinations demonstrated the following: liver function tests revealed alanine amino transferase (ALT) $298 \mathrm{U} / \mathrm{L}$, aspartate aminotransferase (AST) $578 \mathrm{U} / \mathrm{L}$, total bilirubin (TBIL) $185.2 \mu \mathrm{mol} / \mathrm{L}$, direct bilirubin (DBIL) 122.2 $\mu \mathrm{mol} / \mathrm{L}, \mathrm{CHE}$ 15,974.4 U/L, albumin (ALB) $29 \mathrm{~g} / \mathrm{L}, \mathrm{A} / \mathrm{G}$ 1.38. Hepatitis B infection markers were negative. The abdominal ultrasound showed an enlarged liver, echo enhancement, enlarged hepatic portal vein lymph nodes, a thickened gallbladder, splenomegaly and abnormal pancreatic and renal vein structure and hemodynamics. Antinuclear antibody spectrum revealed the following: nRNP/Sm +, anti-dsDNA ++ and ANUA ++. The patient's immunoglobulin values were as follows: C3 $0.63 \mathrm{~g} / \mathrm{L}, \mathrm{C} 40.08 \mathrm{~g} / \mathrm{L}$. His throat swab indicated mycoplasma pneumonia with $5.88 \times 10^{3} /$ copy. Rheumatoid factor was also positive. A biopsy of skin lesions from his palms (Figure 3) revealed histological hallmarks of erythema multiforme (EM) including lymphocytic infiltrate at the dermal-epidermal junction and widespread keratinocyte necrosis. Immunofluorescence examinations were not carried out because the patient can not afford the pay for these examinations. In addition, immunofluorescence examinations were not dispensable for his diagnosis.

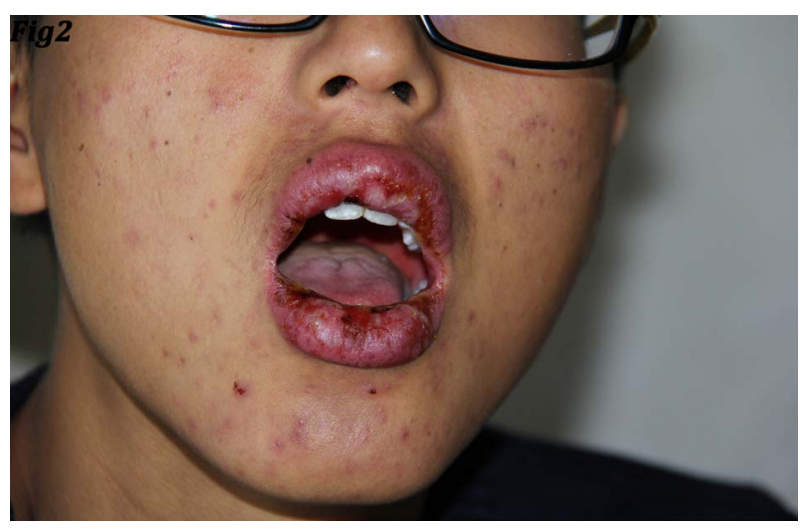

Figure 2. Chapped and bleeding lips, ulcerated oral mucosa, and the pharynx was covered with a white pseudomembrane.

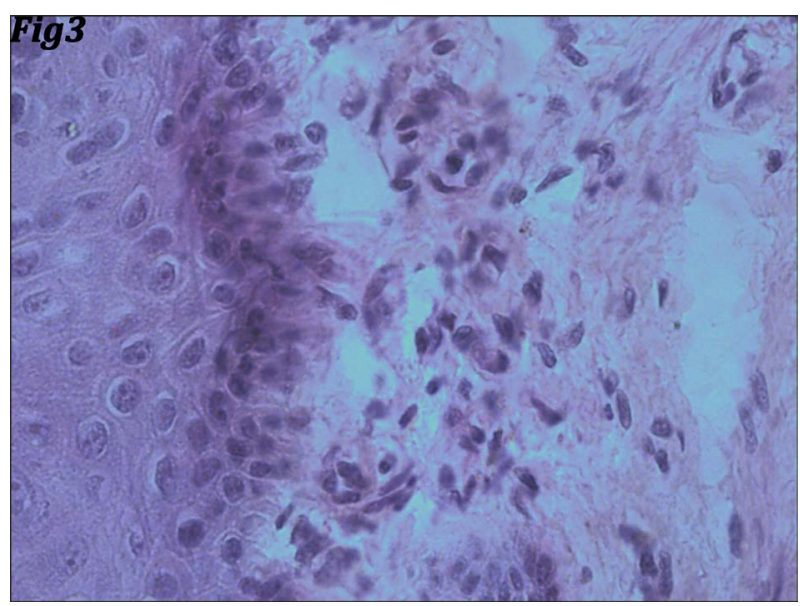

Figure 3. Lymphocytic infiltrate and widespread keratinocyte necrosis at the dermal-epidermal junction. 
He was treated with methylprednisolone $240 \mathrm{mg}$ for 3 days and then oral methylprednisolone tablets $60 \mathrm{mg} /$ day for a duration of one week (followed by tapering of $2.5 \mathrm{mg}$ fortnightly), mycophenolate mofetil $1500 \mathrm{mg} / \mathrm{day}$, hydroxychloroquine $400 \mathrm{mg} /$ day and beta blockers (atenolol $25 \mathrm{mg} /$ day). His clinical and laboratory parameters improved gradually over 3 weeks and he was discharged. He is being followed up regularly and is symptomatically and clinically better.

\section{Discussion}

After RS was first described by Rowell in 1963, Zeitouni et al. revised the diagnostic criteria for RS by three major and three minor criteria. The major criteria consist of the presence of lupus erythematosus (systemic, discoid, or subacute lupus), EM-like lesions (with or without involvement of mucous membranes), and a speckled pattern of antinuclear antibodies. The minor criteria include chilblains, anti-Ro and/or anti-La antibodies, and positive RF [4]. All three major and at least one minor criteria must be present for a diagnosis of RS.

Up to now, more than 40 cases of Rowell syndrome have been reported, most of which lacked the criteria originally described by Rowell et al. or Zeitouni et al. [5]. In most cases, the coexistence of lupus erythematosus and erythema multiforme is a kind of overlap syndrome [6].

This patient's manifestation indicated RS, because his diagnosis of Systemic lupus erythematosus was definite, and also occurred with EM-like lesions and positive antinuclear antibodies. All these above are consistent with the three major criteria. In addition, his RF was positive and this was the complement for the minor criteria. However, therapeutic options for this type of presentation are not well-documented.

Drug-induced hepatitis is one of the more common causes of liver damage in SLE patients. If the patient presents with fever, rash, decreased white blood cells, (acidophilic cells $>6 \%$ ), drug-induced liver damage is a possibility [7]. SLE can also cause liver damage early in the disease course ( $\leq 3$ months). The incidence of liver damage is up to $20 \%-30 \%$ [8] and some researchers think anti-ribosomal $\mathrm{P}$ antibody is implicated [9] [10]. However, the mechanism is unclear, often manifest as hepatomegaly and/or abnormal liver function [11].

Several therapeutic regimens are known, including corticosteroids, methotrexate, dapsone, hydroxychloroquine, and azathioprine [12]. In the majority of cases, these drugs have been used to treat underlying lupus erythematosus. Maybe because EM always caused by drug eruption or virus infection that can also be cured with corticosteroids.

\section{Acknowledgements}

We would like to thank Editage [http://www.editage.cn/] for English language editing. 


\section{Conflicts of Interest}

The authors declare no conflicts of interest regarding the publication of this paper.

\section{References}

[1] Marzano, A.V., Ramoni, S., Del Papa, N., et al. (2008) Leflunomide-Induced Subacute Cutaneous Lupus Erythematosus with Erythema Multiforme-Like Lesions. Lupus, 17, 329-331. https://doi.org/10.1177/0961203307087189

[2] Duarte, A.F., Mota, A., Pereira, M., et al. (2008) Rowell Syndrome: Case Report and Review of the Literature. Dermatology Online Journal, 14, 15.

[3] Kavanaugh, A., Tomar, R., Reveille, J., Solomon, D.H. and Homburger, H.A. (2000) Guidelines for Clinical Use of the Antinuclear Antibody Test and Tests for Specific Autoantibodies to Nuclear Antigens. American College of Pathologists. Archives of Pathology \& Laboratory Medicine, 124, 71-81.

[4] Zeitouni, N.C., Funaro, D., Cloutier, R.A., et al. (2000) Redefining Rowell's Syndrome. British Journal of Dermatology, 142, 343-346.

https://doi.org/10.1046/j.1365-2133.2000.03306.x

[5] Rowell, N.R., Beck, J.S. and Anderson, J.R. (1963) Lupus Erythematosus and Erythema Multiforme-Like Lesions. A Syndrome with Characteristic Immunological Abnormalities. Archives of Dermatology, 88, 176-180.

https://doi.org/10.1001/archderm.1963.01590200064012

[6] Shteyngarts, A.R., Warner, M.R. and Camisa, C. (1999) Lupus Erythematosus Associated with Erythema Multiforme: Does Rowell's Syndrome Exist? Journal of the American Academy of Dermatology, 40, 773-777. https://doi.org/10.1016/S0190-9622(99)70165-9

[7] Noritake, H., Kobayashi, Y., Soda, K., et al. (2010) A Case of Systemic Lupus Erythematosus with Liver Damage. Nihon Shokakibyo Gakkai Zasshi, 107, 915-922.

[8] Decker, J.L., Steinberg, A.D., Gershwin, M.E., et al. (1975) Systemic Lupus Erythematosus. Contrasts and Comparisons. Annals of Internal Medicine, 82, 391-404. https://doi.org/10.7326/0003-4819-82-3-391

[9] Ohira, H., Takiguchi, J., Rai, T., et al. (2004) High Frequency of Anti-Ribosomal P Antibody in Patients with Systemic Lupus Erythematosus-Associated Hepatitis. Hepatology Research, 28, 137-139. https://doi.org/10.1016/j.hepres.2003.11.008

[10] Eber, T., Chapman, J. and Shoenfeld, Y. (2005) Anti-Ribosomal P-Protein and Its Role in Psychiatric Manifestations of Systemic Lupus Erythematosus: Myth or Reality? Lupus, 14, 571-575. https://doi.org/10.1191/0961203305lu2150rr

[11] Gibson, T. and Myers, A.R. (1981) Subclinical Liver Disease in Systemic Lupus Erythematosus. The Journal of Rheumatolog, 8, 752-759.

[12] Shadid, N.H., Thissen, C.A., van Marion, A.M., et al. (2007) Lupus Erythematosus Associated with Erythema Multiforme: Rowell's Syndrome. International Journal of Dermatology, 46, 30-32. https://doi.org/10.1111/j.1365-4632.2007.03508.x 